\title{
Estimation des coûts de production en phytosanitaires pour les grandes cultures. Une approche par la régression quantile
}

Quantile estimates of costs for plant protection in field crops

Dominique Desbois, Jean-Pierre Butault et Yves Surry

\section{(2) OpenEdition}

Journals

Édition électronique

URL : http://journals.openedition.org/economierurale/3857

DOI : 10.4000/economierurale.3857

ISSN : 2105-2581

Éditeur

Société Française d'Économie Rurale (SFER)

Édition imprimée

Date de publication : 15 février 2013

Pagination : 27-49

ISSN : 0013-0559

Référence électronique

Dominique Desbois, Jean-Pierre Butault et Yves Surry, « Estimation des coûts de production en phytosanitaires pour les grandes cultures. Une approche par la régression quantile », Économie rurale [En ligne], 333 | janvier-février 2013, mis en ligne le 15 février 2015, consulté le 10 décembre 2020. URL : http://journals.openedition.org/economierurale/3857 ; DOI : https://doi.org/10.4000/ economierurale.3857 


\section{Estimation des coûts de production en phytosanitaires pour les grandes cultures Une approche par la régression quantile}

Dominique DESBOIS • UMR Économie Publique, INRA-AgroParisTech Jean-Pierre BUTAULT • UMR Économie Publique, INRA-AgroParisTech Yves SURRY • Swedish University of Agricultural Sciences, Uppsala, Suède

Le but de cet article est de proposer une méthodologie d'estimation des coûts de production agricole en phytosanitaires pour les grandes cultures permettant de prendre en compte la variabilité des dépenses induite par l'hétérogénéité des profils d'usage des exploitants agricoles. Après avoir rappelé le contexte institutionnel dans lequel s'impose l'objectif de réduction des phytosanitaires, les auteurs présentent l'approche par la régression quantile, méthodologie retenue afin d'évaluer les coûts en phytosanitaires pour les grandes cultures en France. Puis, ils détaillent les estimations obtenues selon d'une part les critères d'estimation (surfaces ou produits bruts) et, d'autre part, les types de structure (bassin de production, orientation technico-économique, classe de dimension économique). Enfin, ils discutent de la validité empirique des résultats et suggèrent une extension de ces analyses au plan européen.

MOTS-CLÉS : Modélisation input-output, Coûts de production agricole, Analyse micro-économique Quantile estimates of costs for plant protection in field crops

The objective of this paper is to propose an econometric methodology aimed at estimating production costs in plant protection for field crops, using farm accounting data. Following an introductory and brief overview of the institutional framework underlying a strategy to reduce in the medium run the use of pesticides in France, we present the proposed methodology based on quantile regression and applied to plant protection costs for field crops produced by French farmers. Then, we present and discuss the estimated cost results obtained on a per hectare or output unit basis and based on the structural indicators of French farm holdings such as production areas, types of farming and economic size. Finally, we discuss the empirical validity of those estimated cost results and suggest extending the application of the proposed quantile regression to other European countries. (JEL: D2, R15, Q12)

KEY-WORDS: Production, Econometrics and Input-Output Models, Micro Analysis of Farm Holding

\section{Objectif de réduction des phytosanitaires et problématique de l'estimation des coûts de production}

C ompte tenu d'un régime de prix favorable et de débouchés garantis par les orientations initiales de la Politique agricole commune, l'agriculture française a, jusqu'à un passé récent, largement privilégié une orientation productiviste basée sur un recours intensif aux intrants, y compris phytosanitaires, avec pour objectif la croissance des rendements synonyme de progression des revenus. La France consommant plus de 85500 tonnes de matières actives (estimation triennale [2001-2003]) représente plus de $10 \%$ de la consommation de la zone OCDE (OCDE, 2008). Bien qu'il faille rapporter cette consommation à une surface importante de 19,5 millions d'hectares de terres cultivées, elle figure néanmoins au $6^{\mathrm{e}}$ rang de l'Union européenne pour la consommation de phytosanitaires avec 4,4 kg par hectare de terres arables et cultures permanentes (donc hors surfaces en herbe) pour cette période. Le tonnage de matière 


\section{Grandes cultures : coût de production en phytosanitaires}

active a diminué de $10 \%$ entre les périodes [1990-1992] et [2001-2003], ce qui situe la France au-delà de la moyenne OCDE $(-5 \%)$ et a fortiori des pays européens (-4\% pour 1'UE-15), mais bien en deçà du Danemark (-37\%), doté depuis 1986 d'une politique publique de réduction des phytosanitaires basée sur un indicateur de pression environnementale.

Au plan européen, la directive sur les produits phytopharmaceutiques (Règlement CE n¹107/2009), promulguée le 21 octobre 2009 pour une mise en application en 2011 par les États membres, instaure un cadre d'action communautaire pour parvenir à une utilisation durable des phytosanitaires.

Au plan national, le Grenelle de l'environnement s'est fixé comme objectif de réduire l'usage des produits phytosanitaires de $50 \%$ dans un délai inférieur à dix ans. Correspondant à cet objectif, le plan d'action Ecophyto 2018 a été soumis au Gouvernement (Paillotin, 2008). Un des objectifs majeurs de ce plan est de développer des systèmes de culture économes en phytosanitaires. Parmi les principaux moyens envisagés figurent : i) l'extension des pratiques de rotations culturales entre les céréales, oléagineux, protéagineux, les autres cultures et les prairies ; ii) l'élimination des sources d'inefficacité en agriculture conventionnelle; et iii) l'amélioration des connaissances scientifiques et techniques en agronomie. Conformément à cet engagement national pour l'environnement, le Comité opérationnel (COMOP) a rendu ses conclusions le 15 mai 2009 proposant un dispositif de certification environnementale des exploitations agricoles en trois niveaux, dont le troisième, certifie des performances environnementales mesurées et atteintes.

Un des problèmes majeurs dans l'utilisation d'un programme d'optimisation pour l'analyse et la modélisation du comportement des agriculteurs réside dans l'agrégation des données disponibles. D'une part, les dépenses en matière d'herbicides, d'insecticides et de fongicides ne sont disponibles au plan comptable que sous la forme d'un seul agrégat intitulé « dépenses phytosanitaires ». D'autre part, ces dépenses sont en général considérées au niveau de l'exploitation et non par culture. Dans le cas où ces données existent, elles sont tirées de comptabilités analytiques d'exploitations et leur couverture demeure partielle en termes de conditions pédoclimatiques et de systèmes de culture.

Nous proposons d'apporter des éléments de solution à ce problème en estimant les dépenses phytosanitaires selon différents produits culturaux et profils d'allocation de surface pour les principales grandes cultures $^{1}$. Afin d'obtenir une affectation de ces dépenses globales en phytosanitaires à chacune des productions de l'exploitation agricole selon les produits culturaux ou les surfaces allouées, nous présentons des modèles d'estimation du coût en traitement phytosanitaire pour l'ensemble des exploitations agricoles françaises de grande culture en 2006 sur la base du Réseau d'information comptable agricole (RICA). Ces modèles permettront d'effectuer des comparaisons régionales. Cette étude expose une méthodologie robuste d'estimation des dépenses phytosanitaires par culture reposant sur la régression quantile et permettant de prendre en compte la variabilité des dépenses induite par l'hétérogénéité des profils de traitement des exploitants agricoles. En procédant de cette manière, il est possible d'obtenir une

1. La procédure développée dans cet article est à distinguer des approches microéconomiques développées par Boussemart et al. (2011) et Jacquet et al. (2011) visant à analyser le comportement et l'adaptation des agriculteurs français face à une réduction importante de l'usage des pesticides. En ce qui nous concerne, l'objectif est de fournir des informations quantitatives sur la distribution des coûts des phytosanitaires par cultures, qui peuvent être ensuite utilisées dans les modèles ou travaux microéconomiques susmentionnés. 
distribution estimée du coût des phytosanitaires pour les principaux produits de grande culture. Sur la base des résultats obtenus, nous analysons ensuite la variabilité d'usage des phytosanitaires de façon empirique en fonction du facteur régional, de l'orientation technico-économique et de la classe de dimension économique.

\section{Méthodologie d'estimation des dépenses phytosanitaires par culture}

\section{La spécification initiale du modèle coûts de production}

En dépit d'une tendance à la spécialisation, la plupart des exploitations agricoles actuelles dans l'Union européenne (UE) s'inscrivent dans un schéma multi-produits. Dans les systèmes de comptabilités agricoles de l'UE, l'enregistrement des charges s'effectue de manière agrégée au niveau de l'exploitation et ne fournit pas d'estimation directe des coûts de production supportés par cette exploitation pour chacune des spéculations agricoles entreprises. En revanche, la «fiche d'exploitation $»^{2}$ de l'enquête RICA fournit individuellement par exploitation agricole l'enregistrement comptable de chaque poste de charges - en particulier celui des « dépenses phytosanitaires $»^{3}-$ et le montant des produits bruts générés par les différentes spéculations. De sorte qu'il devient possible, par un système de régression des charges sur les produits bruts, d'estimer des coefficients

2. Le questionnaire servant à établir cette « fiche d'exploitation » et la méthodologie de l'enquête RICA sont disponibles à l'adresse : http://wwww.agreste. agriculture.gouv.fr/enquetes/reseau-d-informationcomptable-610/reseau-d-information-comptable.

3. Les dépenses en produits phytosanitaires sont définies dans le RICA par la charge réelle (CHRPH) calculée comme la somme de l'inventaire de début d'exercice comptable (DEBPH) et des achats au cours de l'exercice (ACHPH) à laquelle on retranche l'inventaire de fin d'exercice (FINPH). d'affectation des dépenses aux principaux produits agricoles, appelés «coefficients techniques de production ». En disposant ce système de relations comptables pour l'exploitation (indice $i$ ) sous la forme d'un tableau où les colonnes représentent les biens agricoles produits (indice $j$ ) et les lignes les facteurs de production (indice $k$ ), on obtient une matrice d'entrées-sorties, d'où la dénomination alternative : « coefficient d'input-output ${ }^{4}$.

La spécification du Modèle coûts de production $(\mathrm{MCP})$ dont nous partons pour exposer ce problème d'estimation, est basée sur une fonction de coût linéaire à coefficients constants: les charges sont supposées proportionnelles aux produits bruts ou aux surfaces cultivées afférents. Pour chaque charge $X_{k}$, la version initiale du modèle d'estimation des coûts de production agricoles cherche à estimer sur chacun des produits bruts ou des surfaces cultivées $Y_{j}$, les coefficients techniques de production $a_{k}^{j}$ dans l'équation de régression suivante appliquée à l'ensemble des exploitations du RICA :

$$
\text { (1) } X_{i k}=\sum_{j=1}^{p} \alpha_{k}^{j} Y_{i j}+\varepsilon_{i k} \text { avec } \varepsilon_{i k} \text { i.i.d. }
$$

L'équation (1) a été initialement estimée par l'ajustement des moindres carrés ordinaires (MCO) (Bureau et Cyncynatus, 1991). Cette méthode numériquement adaptée à l'estimation des fonctions de coûts linéaires, fournit l'estimateur sans biais de variance minimale des coefficients techniques de production, pourvu que les hypothèses ${ }^{5}$ stochastiques du modèle soient respectées.

4. Ces coefficients peuvent s'interpréter comme une estimation de la dépense moyenne relative à l'intrant $k$ nécessaire pour produire une unité monétaire du bien agricole $j$.

5. Ces hypothèses se résument comme suit: erreurs aléatoires $\varepsilon_{i k}$ indépendantes et identiquement distribuées selon une loi normale $\mathrm{N}(0, \sigma)$ de variance constante $\sigma^{2}$. 


\section{Grandes cultures : coût de production en phytosanitaires}

La spécification initiale permet de s'appuyer sur des procédures de régression linéaire conservant l'égalité comptable liant le revenu au produit brut et aux charges par la prise en compte de contraintes d'estimation (Desbois et Pollet, 2002 ; Pollet et al., 1998). Cependant, elle fait reposer l'estimation des coûts de production sur le postulat d'un standard technico-économique commun à l'ensemble des exploitations agricoles de grandes cultures où les coefficients techniques de production $a_{k}^{j}$ ne seraient fonction que de la nature du produit et non pas des différents paramètres qui caractérisent les exploitations agricoles, notamment taille, contexte pédoclimatique et système de production. Les céréales étant présentées comme la production agricole la plus sensible aux effets d'échelle, nous testerons empiriquement l'hypothèse d'une économie de dimension pour les coûts en phytosanitaires en analysant les résultats selon le critère de la dimension économique (cf. infra, Estimation comparée des coûts en phytosanitaires).

Tout en fournissant des résultats économétriques qui sont, de prime abord, satisfaisants, la spécification MCP soulève certains problèmes qu'il ne faut pas ignorer. Tout d'abord, dans un contexte d'utilisation mobilisant le RICA français comme base empirique d'estimation des coûts de production, les hypothèses stochastiques du MCP peuvent ne pas être respectées : ainsi, l'asymétrie des distributions de charges phytosanitaires (concentration pour les valeurs plus faibles et dispersion des valeurs plus élevées que la moyenne) conduit au rejet de l'hypothèse de normalité des erreurs. En outre, compte tenu du mode de sélection spécifique au RICA français (enquête selon la méthode des quotas), les données comptables ne sont pas collectées suivant un plan de sondage aléatoire stratifié permettant de délivrer selon un raisonnement inférentiel une estimation par intervalle.
Au plan empirique, les résultats du MCP apparaissent assez fiables pour les céréales quand l'intra-consommation (consommation intermédiaire par l'exploitation agricole de ses propres produits) n'est pas dominante. Dans le cas contraire, dans la mesure où les produits agricoles intraconsommés ne sont pas pris en compte dans le calcul du produit, l'estimation du coefficient technique de production correspondant, peut être biaisée. C'est le cas pour certaines cultures de plein champ, notamment les céréales, où l'intra-consommation de semences n'est pas négligeable. Cependant, à moins de considérer que certaines pratiques (allongement des rotations culturales, désherbage mécanique) viendraient se substituer préventivement aux traitements phytosanitaires, nous faisons l'hypothèse que l'intra-consommation de produits phytosanitaires est négligeable.

\section{La régression quantile}

La régression quantile a été développée par Koenker et Bassett (1978) afin de prendre en compte l'hétérogénéité de l'ensemble des valeurs d'une variable endogène $x$ dans le contexte d'un modèle linéaire ${ }^{6}$. Lorsqu'on s'intéresse aux exploitations agricoles, cette méthode économétrique permet d'obtenir une distribution estimée du coût des phytosanitaires pour les principaux produits de grande culture et ainsi complète les estimations obtenues par $\mathrm{MCO}$, qui ne fournissent qu'une valeur moyenne (en termes d'espérance) de ces mêmes coûts. Au lieu d'une estimation par intervalle bâtie sur une hypothèse de normalité, le processus quantile fournit une distribution empirique des estimations sans avoir à formuler d'hypothèses sur la nature de cette distribution ni à suivre un plan de sondage aléatoire stratifié.

6. Pour une présentation détaillée et concise de la régression quantile, voir le livre de Koenker (2005). 
Pour une variable aléatoire $(\mathrm{va})$ continue $x$, le $q^{\text {ieme }}$ quantile de la population est la valeur $\mu_{q}$ telle que $x$ soit inférieure ou égale à $\mu_{q}$ avec la probabilité $q$. Ainsi, peut-on écrire :

(2) $q=\operatorname{Pr}\left[x \leq \mu_{q}\right]=F_{x}\left(\mu_{q}\right)$

où $F_{x}$ est la fonction de répartition (FDR) de $x$ donnant la probabilité cumulée d'une valeur sous la loi de $x$.

Le $q^{\text {ième }}$ quantile se définit alors comme l'image de la valeur $q$ par la fonction réciproque de la FDR :

(3) $\mu_{q}=F_{x}^{-1}(q)$.

En régression quantile, le $q^{\text {ième }}$ quantile conditionnel du coût de production $x$ conditionné par l'ensemble des variables exogènes $Y$ déterminant la consommation d'intrants est la fonction indicée $\mu_{q}(Y)$ telle que la variable aléatoire « $x$ sachant $Y$ » soit inférieure ou égale à $\mu_{q}(Y)$ avec la probabilité $q$. Ainsi, on peut définir formellement le $q^{\text {ième }}$ quantile conditionnel par l'expression suivante :

(4) $\mu_{q}(Y)=F_{x / Y}^{-1}(q)$

où $F_{x / Y}$ est la fonction de répartition de la loi de $x$ conditionnée par $Y$.

À l'instar de Cameron et Trivedi (2005), supposons que le processus générateur de données soit un modèle linéaire à hétéroscédasticité multiplicative :

(5) $x=Y^{\prime} \beta+u$ avec $u=Y^{\prime} \alpha \times \varepsilon$

où $\varepsilon$ est un vecteur d'aléas identiquement et indépendamment distribués de moyenne nulle et de variance constante $\sigma^{2}$, c'est-à-dire : $\varepsilon \sim$ i.i.d. $\left[0, \sigma^{2}\right]$.

$$
\text { et } Y^{\prime} \alpha>0
$$

Sous cette hypothèse, $\mu_{q}(Y, \beta, \alpha)$, le $q^{\text {ième }}$ quantile conditionnel du coût de production $x$ conditionné par $Y$ et les paramètres $\alpha$ et $\beta$, se déduit analytiquement comme suit $^{7}$ :

(6) $\mu_{q}(Y, \beta, \alpha)=Y^{\prime}\left[\beta+\alpha \times F_{\varepsilon}^{-1}(q)\right]$

où $F_{\varepsilon}$ est la FDR de la loi de $\varepsilon$.

Ainsi, pour un processus générateur de données suivant un modèle linéaire à hétéroscédasticité multiplicative (i.e. $u=Y^{\prime} \alpha \times \varepsilon$ ), le $q^{\text {ième }}$ quantile conditionnel du coût de production $x$ conditionné par les facteurs exogènes $Y$ est linéaire en $Y$. De plus, l'estimation des paramètres associés à la $q^{\text {ième }}$ régression quantile converge vers $\beta+\alpha \times F_{\varepsilon}^{-1}(q)$ et en conséquence se comporte de manière identique et monotone vis-à-vis de l'évolution du quantile $q$, dépendant bien sûr de la fonction quantile des résidus, $F_{\varepsilon}^{-1}(q)$. L'homoscédasticité correspond au cas particulier de cette spécification où $Y^{\prime} \alpha$ est constant : cela signifie que tous les quantiles conditionnels, présentant alors la même pente, ne différent que par une constante qui croît au fur et à mesure que l'ordre $q$ du quantile augmente.

La procédure d'estimation utilisée en régression quantile, présentée dans

7.L'équation (6) se déduit comme suit :

$$
\begin{aligned}
q=\operatorname{Pr}\left(x \leq \mu_{q}\right) & =\operatorname{Pr}\left[x \leq \mu_{q}(Y, \beta, \alpha)\right] \\
& =\operatorname{Pr}\left[u \leq \mu_{q}(Y, \beta, \alpha)-Y^{\prime} \beta\right] \\
& =\operatorname{Pr}\left[\varepsilon \leq \frac{\mu_{q}(Y, \beta, \alpha)-Y^{\prime} \beta}{Y^{\prime} \alpha}\right] \\
& =F_{\varepsilon}\left(\frac{\left[\mu_{q}(Y, \beta, \alpha)-Y^{\prime} \beta\right]}{Y^{\prime} \alpha}\right)
\end{aligned}
$$

où nous avons fait usage des formules suivantes : $u=x-Y^{\prime} \beta$ et $\varepsilon=u / Y^{\prime} \alpha$.

De l'expression (6a), il s'ensuit que

$\frac{\left[\mu_{q}(Y, \beta, \alpha)-Y^{\prime} \beta\right]}{Y^{\prime} \alpha}=F_{\varepsilon}^{-1}(q) \quad$ et

$$
\begin{aligned}
\mu_{q}(\mathrm{Y}, \beta, \alpha) & =\mathrm{Y}^{\prime} \beta+\mathrm{Y}^{\prime} \alpha \times F_{\varepsilon}^{-1}(q) \\
& =\mathrm{Y}^{\prime}\left(\beta+\alpha \times F_{\varepsilon}^{-1}(q)\right)
\end{aligned}
$$




\section{Grandes cultures : coût de production en phytosanitaires}

l'encadré ci-après, repose sur la norme des écarts en valeur absolue. Cela implique que l'estimation est moins sensible aux valeurs extrêmes de la variable endogène que la régression $\mathrm{MCO}$ dont l'ajustement s'opère selon la norme du carré des écarts résiduels. Ainsi la régression quantile permet-elle d'explorer l'hétérogénéité des profils de dépenses en inférant, de façon robuste en fonction de chaque quantile de dépenses phytosanitaires, un profil d'allocation de ce facteur de production conditionnellement soit aux allocations de surfaces pour les différentes cultures, soit au produit brut généré par les cultures présentes sur l'exploitation agricole.

\section{Bases empiriques de l'estimation}

L'enregistrement effectué par le RICA des dépenses en produits de protection des cultures ainsi que des surfaces allouées annuellement aux cultures et des produits récoltés constitue la base empirique de notre estimation des coûts phytosanitaires. Il fournit ainsi un détail des charges d'exploitation permettant de connaître chaque année la dépense en produits phytosanitaires. Le RICA fournit également les allocations de surface pour chacune des cultures et les montants des produits bruts obtenus pour chacun des produits correspondants.

L'unité statistique du RICA est l'exploitation agricole; sa représentativité est assurée - sur une base régionale et technico-économique - par un échantillonnage conduit d'après une sélection sur quotas et prenant en compte d'une part, la région au niveau II de la Nomenclature des unités territoriales statistiques de l'Union européenne (NUTS), et d'autre part la répartition de la marge brute standard de l'exploitation selon les deux critères que sont l'orientation technico-économique et la classe de dimension économique. La périodicité du RICA est annuelle et l'enquête est réalisée dans chacun des États membres de l'UE selon des concepts et définitions harmonisés.

La population de référence est celle des exploitations de grandes cultures, comprenant les orientations technico-économiques (Otex) suivantes : céréales, oléagineux, protéagineux (Otex 13), cultures générales (Otex 14) et grandes cultures et herbivores (Otex 81), soit un sous-échantillon de 2551 exploitations sur les 7344 de l'échantillon français du RICA en 2006. Un aperçu sur les principales caractéristiques de cet échantillon des exploitations agricoles apparaît au tableau 1 (p. 34). Chaque exploitation de l'échantillon est affectée d'un poids calculé comme l'inverse du taux de sondage de chaque strate définie par le croisement des trois critères structuraux: région, organisation technico-économique et classe de dimension économique. L'utilisation de cette pondération permet à partir des estimations pondérées de reconstituer les dépenses phytosanitaires correspondantes au niveau macroéconomique $^{8}$. Pour tenir compte des «queues de quota», la pondération du RICA est réalisée a posteriori par un algorithme de calage sur marges selon la méthode du logit produisant des poids positifs et permettant un contrôle du rapport des poids (Deville, Särndal et Sautory, 1993).

8. D'un point de vue économétrique, l'adjonction de poids à chaque observation de l'échantillon RICA permet aussi de rendre compte de l'hétérogénéité existant dans la population des exploitations agricoles françaises et conduit ainsi à une amélioration en termes d'efficacité des estimateurs tant de la régression quantile que des MCO. 


\section{Procédure d'estimation de la régression quantile}

Pour chaque quantile d'ordre $q$, la régression quantile est estimée comme la solution d'un problème de minimisation selon le critère de l'écart en valeur absolue (norme $L 1$ ) :

(7) $\hat{\beta}(q)=\underset{\beta \in \mathfrak{Y}^{p}}{\arg \min }\left\{\sum_{i \in\left\{i / x_{i} \geq y_{i}^{\prime} \beta\right\}} q\left|x_{i}-y_{i}^{\prime} \beta\right|+\sum_{\left.i \in\left\{i / x_{i} \leq y_{i}^{\prime}\right\}\right\}}(1-q)\left|x_{i}-y_{i}^{\prime} \beta\right|\right\}$.

Les quantiles conditionnels pondérés ont été proposés comme L-estimations ${ }^{9}$ dans des modèles linéaires hétéroscédastiques par Koenker et Zhao (1994) définie par $\left\{\omega_{i} ; \mathrm{i}=1, \ldots, n\right\}$, la pondération $\omega$ des observations conduit à un schéma de régression quantile résolvant le problème de minimisation suivant :

(8) $\hat{\beta}_{\omega}(q)=\underset{\beta \in \Re^{p}}{\arg \min }\left\{\sum_{i \in\left\{i / x_{i} \geq y_{i}^{\prime} \beta\right\}} \omega_{i} q\left|x_{i}-y_{i}^{\prime} \beta\right|+\sum_{i \in\left\{i / x_{i} \leq y_{i} \beta\right\}} \omega_{i}(1-q)\left|x_{i}-y_{i}^{\prime} \beta\right|\right\}$.

À l'instar de la régression L1, la régression quantile peut se formuler comme un problème de programmation linéaire en termes standards (Barrodale et Roberts, 1973). Les algorithmes développés pour la régression L1 s'étendent à la régression quantile (Koenker et d'Orey, 1994) en tant que reformulation du problème primal d'optimisation, $\min _{\beta \in \Re^{p}} \sum_{i=1}^{n} \rho_{q}\left(x_{i}-y_{i}^{\prime} \beta\right)$ en une formulation duale du type suivant :

(9) $\operatorname{Max}\left\{x^{\prime} z\right\}$

sous la contrainte $Y^{\prime \prime} z=(1-q) Y^{\prime} e$ pour $\mathrm{z} \in[0,1]^{\mathrm{n}}$.

Pour les échantillons de grande taille, Portnoy et Koenker (1997) ont montré qu'une combinaison de l'algorithme du " point intérieur $\aleph^{10}$ (Karmakar, 1984) et d'un prétraitement adapté rend les calculs de la régression quantile compétitifs avec ceux de la régression des moindres carrés. Compte tenu de la taille de l'échantillon RICA, de sa sélection non-aléatoire et de l'existence de trois sous-populations a priori distinctes (Otex), nous utilisons la méthode du ré-échantillonnage, basée sur la technique du bootstrap car, sans hypothèse sur les distributions, elle donne des intervalles de confiance empiriques en un temps de calcul raisonnable.

\section{Estimation comparée des coûts en phytosanitaires}

Dans cette partie sont réunis et discutés les résultats économétriques de la régression quantile appliquée au modèle coût de production (MCP) représenté par l'expression (6). L'estimation à l'aide du programme QUANTREG du logiciel SAS a été effectuée

9. Estimation robuste définie, telle que la médiane ou les moyennes tronquées, par une combinaison linéaire de statistiques ordinales.

10. La procédure QUANTREG de SAS 9.2 utilise l'implantation prédicteur-correcteur de l'algorithme primal-dual, proposée par Lustig et al. (1992). La pondération $\omega$ est introduite par l'instruction weight du logiciel. pour deux spécifications de ce modèle, la première reposant sur des variables explicatives représentant les produits bruts des grandes cultures et la deuxième en fonction des surfaces cultivées exprimées en hectares. Dans les deux cas, les variables explicatives sont au nombre de 13 ou $14^{11}$, comprenant ainsi l'ensemble des grandes cultures produites

11. Pour la spécification MCP, selon les produits bruts, les variables explicatives exprimées en euros sont : blé tendre, blé dur, orge, maïs grain, autres céréales, pomme de terre, betterave sucrière, protéagineux, tournesol, colza, autres oléagineux, autres cultures et autres produits bruts. Pour la spécification selon les surfaces, nous avons les mêmes catégories à l'exception de « autres produits bruts », remplacée par la surface fourragère. 
Grandes cultures : coût de production en phytosanitaires

Tableau 1. Descriptif de la base d'estimation RICA 2006 (Moyennes et erreur-type)

\begin{tabular}{|c|c|c|c|c|c|}
\hline Otex & 13 & 14 & 81 & Ensemble & Toutes Otex \\
\hline \multirow[t]{2}{*}{ Charges phyto-sanitaires $€$} & 14098 & 15761 & 8552 & 12799 & 6763 \\
\hline & $(50)$ & (93) & $(40)$ & (35) & (108) \\
\hline \multirow[t]{2}{*}{ Produit brut $€$} & 148715 & 214997 & 181672 & 173561 & 164783 \\
\hline & $(473)$ & $(1$ 146) & (688) & $(407)$ & $(1881)$ \\
\hline \multicolumn{6}{|l|}{ Surfaces ha } \\
\hline \multirow{2}{*}{ Blé tendre } & 43,32 & 37,15 & 26,31 & 36,68 & 24,05 \\
\hline & $(0,16)$ & $(0,22)$ & $(0,11)$ & $(0,10)$ & $(0,41)$ \\
\hline \multirow[t]{2}{*}{ Blé dur } & 29,73 & 28,23 & 18,67 & 28,53 & 22,89 \\
\hline & $(0,28)$ & $(0,54)$ & $(0,41)$ & $(0,23)$ & $(1,12)$ \\
\hline \multirow[t]{2}{*}{ Orge } & 22,90 & 15,97 & 12,50 & 17,95 & 12,43 \\
\hline & $(0,12)$ & $(0,12)$ & $(0,09)$ & $(0,07)$ & $(0,27)$ \\
\hline \multirow[t]{2}{*}{ Maïs grain } & 29,73 & 28,23 & 18,67 & 28,53 & 15,34 \\
\hline & $(0,28)$ & $(0,54)$ & $(0,41)$ & $(0,23)$ & $(0,44)$ \\
\hline \multirow[t]{2}{*}{ Pomme de terre } & 6,57 & 18,74 & 2,80 & 14,30 & 10,70 \\
\hline & $(0,20)$ & $(0,26)$ & $(0,11)$ & $(0,19)$ & $(0,91)$ \\
\hline \multirow{2}{*}{ Betteraves sucrières } & 10,66 & 15,63 & 5,23 & 12,09 & 11,44 \\
\hline & $(0,10)$ & $(0,12)$ & $(0,06)$ & $(0,07)$ & $(0,41)$ \\
\hline \multirow[t]{2}{*}{ Protéagineux } & 12,43 & 9,94 & 6,48 & 10,49 & 9,57 \\
\hline & $(0,09)$ & $(0,08)$ & $(0,07)$ & $(0,05)$ & $(0,29)$ \\
\hline \multirow[t]{2}{*}{ Tournesol } & 18,38 & 10,70 & 10,08 & 15,73 & 13,81 \\
\hline & $(0,10)$ & $(0,14)$ & $(0,10)$ & $(0,08)$ & $(0,41)$ \\
\hline \multirow[t]{2}{*}{ Colza } & 26,56 & 13,94 & 13,89 & 20,77 & 18,02 \\
\hline & $(0,13)$ & $(0,10)$ & $(0,09)$ & $(0,08)$ & $(0,41)$ \\
\hline \multirow[t]{3}{*}{ Fourrages } & 11,66 & 14,03 & 25,75 & 19,97 & 9,56 \\
\hline & $(0,11)$ & $(0,15)$ & $(0,13)$ & $(0,09)$ & $(0,54)$ \\
\hline & $n=1221$ & $n=594$ & $n=736$ & $n=2551$ & $n=7344$ \\
\hline
\end{tabular}

par les exploitations agricoles françaises faisant partie des Otex 13, 14 et 81. En raison d'un manque de place, les estimations des coûts phytosanitaires présentées dans les prochains tableaux se rapportent aux principales grandes cultures produites en France. De plus, ces estimations sont effectuées pour les quartiles conditionnels $Q 1[0,25]$, $Q 2[0,50]$ et $Q 3[0,75]$ et comparées avec l'estimation issue des moindres carrés ordinaires (MCO).

\section{Estimations selon le produit brut}

En effectuant les analyses sur la base du produit brut dégagé par culture, on obtient des estimations pour $1000 €$ de produit brut (tableau 2). Les coefficients estimés conditionnellement au troisième quartile (Q3) sont tous significativement différents de zéro. C'est également le cas pour l'estimation MCO, sauf pour la catégorie « autres oléagineux ». Pour les estimations conditionnelles au premier quartile $(Q 1)$ et la médiane $(Q 2)$, seuls les coefficients se rapportant aux protéagineux et aux autres oléagineux ne sont pas significativement différents de zéro.

Pour ces estimations, le premier quartile conditionnel est inférieur à la médiane conditionnelle, elle-même inférieure au 
RECHERCHES

Dominique DESBOIS, Jean-Pierre BUTAULT, Yves SURRY

Tableau 2. Estimations quartiles et MCO selon le produit brut

\begin{tabular}{|c|c|c|c|c|c|c|c|c|}
\hline \multirow{3}{*}{$\begin{array}{l}€ / 1000 € \\
\text { (erreur-type) } \\
\text { Blé tendre }\end{array}$} & \multirow{2}{*}{\multicolumn{2}{|c|}{ Q1 }} & \multirow{2}{*}{\multicolumn{2}{|c|}{ Q2 }} & \multirow{2}{*}{\multicolumn{2}{|c|}{ Q3 }} & \multirow{2}{*}{\multicolumn{2}{|c|}{ MCO }} \\
\hline & & & & & & & & \\
\hline & $\begin{array}{l}175 \\
(7)\end{array}$ & $* * *$ & $\begin{array}{c}214 \\
(8)\end{array}$ & $* * *$ & $\begin{array}{r}239 \\
(9)\end{array}$ & $* * *$ & $\begin{array}{r}202 \\
(6)\end{array}$ & $* * *$ \\
\hline Blé dur & $\begin{array}{l}109 \\
(10)\end{array}$ & $* * *$ & $\begin{array}{l}143 \\
(14) \\
\end{array}$ & $* * *$ & $\begin{array}{l}202 \\
(21) \\
\end{array}$ & $* * *$ & $\begin{array}{l}156 \\
(10) \\
\end{array}$ & $* * *$ \\
\hline Orge & $\begin{array}{l}155 \\
\text { (14) }\end{array}$ & $* * *$ & $\begin{array}{l}187 \\
(15)\end{array}$ & $* * *$ & $\begin{array}{l}209 \\
(20)\end{array}$ & $* * *$ & $\begin{array}{l}161 \\
(11)\end{array}$ & $* * *$ \\
\hline Maïs grain & $\begin{array}{l}48 \\
\text { (4) }\end{array}$ & $* * *$ & $\begin{array}{l}70 \\
\text { (3) }\end{array}$ & $* * *$ & $\begin{array}{l}87 \\
(5)\end{array}$ & $* * *$ & $\begin{array}{l}64 \\
\text { (4) }\end{array}$ & $* * *$ \\
\hline Pomme de terre & $\begin{array}{l}39 \\
\text { (5) }\end{array}$ & $* * *$ & $\begin{array}{l}58 \\
\text { (7) }\end{array}$ & $* * *$ & $\begin{array}{c}76 \\
(17)\end{array}$ & $* * *$ & $\begin{array}{l}52 \\
(2)\end{array}$ & $* * *$ \\
\hline Betterave sucrière & $\begin{array}{c}71 \\
\text { (11) }\end{array}$ & $* * *$ & $\begin{array}{c}71 \\
(10)\end{array}$ & $* * *$ & $\begin{array}{c}96 \\
(19)\end{array}$ & $* * *$ & $\begin{array}{l}85 \\
\text { (7) }\end{array}$ & $* * *$ \\
\hline Protéagineux & $\begin{array}{c}44 \\
\text { (39) }\end{array}$ & & $\begin{array}{c}57 \\
(42)\end{array}$ & & $\begin{array}{l}133 \\
\text { (62) }\end{array}$ & $* * *$ & $\begin{array}{l}100 \\
(29)\end{array}$ & $* * *$ \\
\hline Tournesol & $\begin{array}{l}172 \\
(22)\end{array}$ & $* * *$ & $\begin{array}{l}188 \\
(18)\end{array}$ & $* * *$ & $\begin{array}{l}202 \\
(27)\end{array}$ & $* * *$ & $\begin{array}{l}172 \\
(21)\end{array}$ & $* * *$ \\
\hline Colza & $\begin{array}{l}184 \\
\text { (17) }\end{array}$ & $* * *$ & $\begin{array}{l}196 \\
(18)\end{array}$ & $* * *$ & $\begin{array}{l}261 \\
(22)\end{array}$ & $* * *$ & $\begin{array}{l}227 \\
(13)\end{array}$ & $* * *$ \\
\hline$n=2551$ & & & & & & & & \\
\hline * significatif à 10 \% & & signif & f à $5 \%$ & & & signi & f à $1 \%$ & \\
\hline
\end{tabular}

Source : RICA 2006

troisième quartile conditionnel, à l'exception de la betterave sucrière où le coefficient estimé selon le premier quartile est égal à celui estimé selon la médiane. Les estimations de tendance centrale, selon la médiane conditionnelle $(Q 2)$ et l'espérance conditionnelle (MCO), sont proches (moins de $10 \%$ d'écart) pour le blé tendre, le blé dur, le maiis et le tournesol, assez proches (moins de $15 \%$ d'écart) pour la pomme de terre et l'orge, assez différentes (plus de $15 \%$ d'écart) pour le colza, les autres céréales et la betterave sucrière. Relativement à l'estimation quantile de type $Q 2$, l'estimation MCO sous-estime les dépenses phytosanitaires pour le blé tendre, l'orge, le maïs, la pomme de terre, les autres céréales et le tournesol, et les surestime dans les autres cas. Si l'on examine l'ensemble du processus quantile pour chacune des cultures, on constate que les coûts phytosanitaires du blé tendre sont significativement croissants selon les quantiles de dépenses en phytosanitaires (figure 1), compte tenu de la dispersion des estimations obtenue à partir du processus de ré-échantillonnage ${ }^{12}$.

Cependant, si l'on compare aux niveaux moyens de l'indice de fréquence de traitement (IFT) issu de l'enquête Pratiques culturales (PK) 2006 (Chapelle-Barry, 2008),

12. Ce résultat est conforme avec l'hypothèse d'hétéroscédasticité multiplicative des résidus dans le modèle MCP [expression (5)], qui entraîne une relation monotone des coefficients estimés vis-à-vis de l'évolution du quantile $q$. Ce phénomène se retrouve pour d'autres résultats présentés et discutés dans cette partie. 


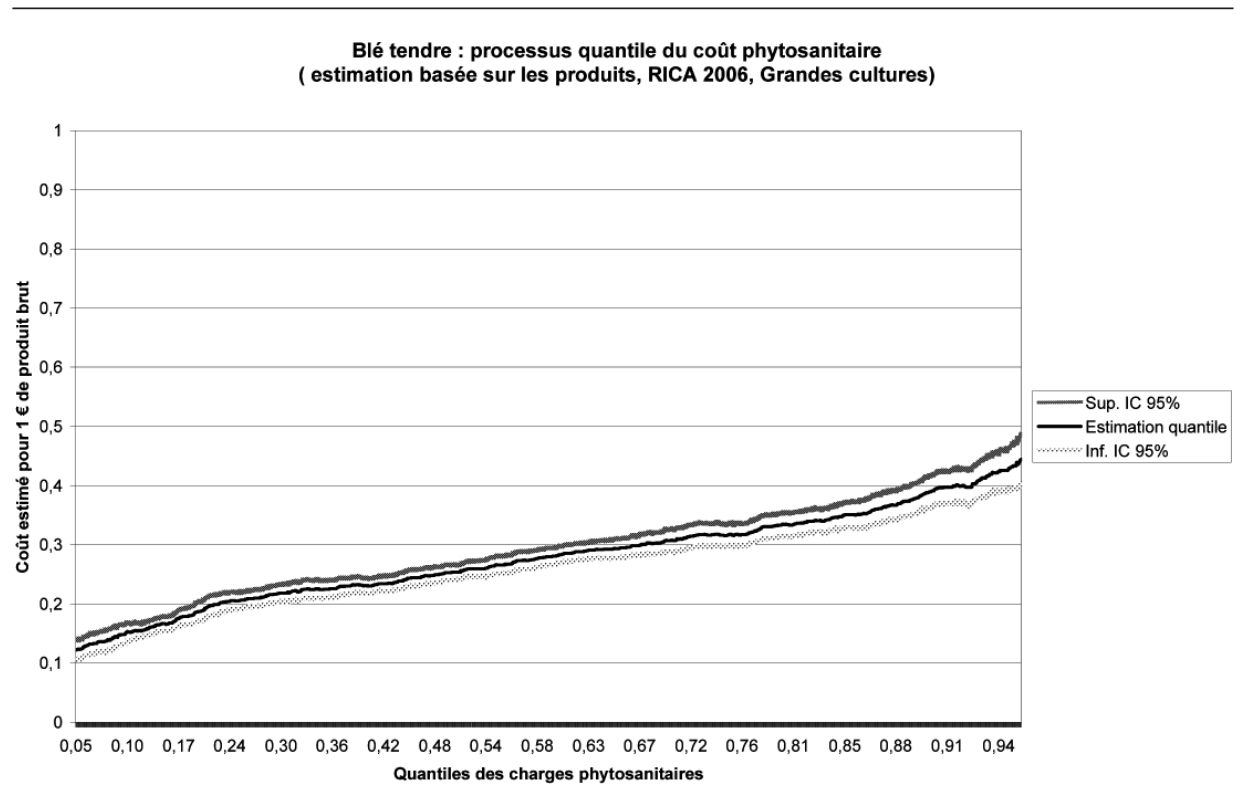

on constate que les ordres de grandeurs relatifs entre céréales sont peu ou prou respectés par la procédure d'estimation médiane des coûts. Ainsi, le rapport des coûts médians du blé tendre à ceux du maïs est de 1,8 alors que le rapport homologue pour l'IFT est de 2. Ce rapport est de 1,4 pour le blé dur relativement au maïs alors que le rapport des IFT est de 1,5. Constat identique pour les oléagineux : le rapport des coûts médians du colza à ceux du tournesol est de 2,6 alors que celui des IFT est de 2,7 .

L'analyse en coupe diachronique ${ }^{13}$ sur la période 1987-2009 montre que les estimations quantiles des coûts phytosanitaires selon le produit brut sont croissantes sur la période pour les céréales, relativement cycliques sur une période raccourcissant

13. Nous ne présentons pas toutes ces informations pour la période 1987-2009 en raison de la masse d'informations disponibles et du manque de place dans le présent article. Cette remarque est aussi valable pour les autres analyses diachroniques effectuées ci-après. de 5 à 3 ans pour la pomme de terre, et décroissantes pour la betterave sucrière.

Les estimations quantiles pour les protéagineux et les oléagineux sont croissantes sur la période 1986-1993 puis varient autour d'une tendance stable sur la période 1994-2005 et décroissantes sur la période 2006-2009. La comparaison avec les observations analytiques, issues des sondes grandes cultures (SGC) du RICA (Île-de-France, Centre et Midi-Pyrénées) et du Centre d'économie rurale (CER) de la Meuse, permet de situer les producteurs de ces bassins relativement à l'ensemble des producteurs français : ainsi, les agriculteurs meusiens présentent les coûts phytosanitaires par euro de produit brut parmi les plus faibles pour les céréales et le colza tandis que les franciliens se situent dans le premier quartile pour la betterave sucrière ; les agriculteurs de Midi-Pyrénées sont proches du coût médian pour le tournesol, et ceux de la région Centre proches du premier quartile pour le blé tendre. 


\section{Estimations selon la surface cultivée}

Sur la base des assolements pratiqués par les exploitations spécialisées en grandes cultures (Otex 13, 14 et 81) du RICA 2006, nous avons effectué des estimations selon les trois quartiles conditionnels ( $Q 1, Q 2$ et $Q 3)$, en comparant avec les estimations MCO pour apprécier l'effet de l'hétérogénéité sur la distribution des estimations (tableau 3). Pour l'estimation menée à partir des surfaces cultivées, les coefficients estimés sont tous significativement différents de zéro, sauf ceux relatifs à la catégorie «autres oléagineux » qui rassemblent des cultures relativement minoritaires en France dont le soja.

Ces estimations conditionnelles selon les quantiles sont croissantes monotones selon le quartile de dépenses phytosanitaires : le premier quartile conditionnel est inférieur à la médiane conditionnelle, elle-même inférieure au troisième quartile conditionnel, à l'exception du tournesol pour lequel l'ordre est inverse et des protéagineux pour lesquels le premier quartile est légèrement supérieur à la médiane conditionnelle. Les estimations de tendance centrale, selon la médiane conditionnelle $Q 2$ et selon l'espérance conditionnelle $(\mathrm{MCO})$, sont très proches (moins de $2 \%$ d'écart) pour le blé tendre, le blé dur, le maïs et la pomme de terre, proches (moins de $10 \%$ d'écart) pour le tournesol, assez proches (moins de $15 \%$ d'écart) pour le colza et l'orge, assez différentes (plus de $15 \%$ d'écart) pour les betteraves sucrières, les fourrages et les protéagineux. Par rapport à l'estimation selon la médiane conditionnelle, l'estimation MCO sous-estime les dépenses phytosanitaires pour l'orge, le maïs, la pomme de terre, la betterave sucrière, le tournesol ou le fourrage (effet des valeurs nulles pour ces distributions de surfaces), et les surestime dans les autres cas (effets des valeurs positives élevées). Pour le maïs, les dépenses phytosanitaires estimées apparaissent plus faibles que pour les autres céréales.

Cependant, si pour les céréales et les oléagineux, les ordres de grandeur internes à chaque type de culture indiquent une correspondance entre l'échelle des estimations obtenues et celle du nombre de traitements appliqués, il n'en est pas de même pour d'autres types de cultures. Ainsi, pour les cultures industrielles, le rapport des coûts médians de la pomme de terre à la betterave sucrière est de 2,1 alors que le rapport des IFT est de 3,8: les profils de coûts entre ces deux cultures industrielles ne semblent pas comparables. De même, les ordres de grandeur des estimations entre les céréales et le colza sont en désaccord avec les IFT respectifs : rapport de 1,5 du colza au blé tendre pour l'IFT alors que le rapport entre les estimations est inférieur à l'unité. Cette analyse empirique montre donc qu'une procédure d'estimation des coûts phytosanitaires devrait tenir compte en première approximation de l'IFT spécifique à chaque type de culture et, le cas échéant, des profils de traitements particuliers appliqués à chaque culture.

Sur l'ensemble du processus quantile, l'estimation selon les surfaces donne pour le blé tendre une distribution similaire à celle selon les produits bruts (figure 1) avec cependant des infléchissements plus marqués pour les quantiles extrêmes de la distribution. Les estimations, selon la surface, sont supérieures sur la période 1987-2009 aux estimations calculées selon le produit pour une surface médiane de blé tendre, de blé dur, d'orge, de protéagineux, de pomme de terre et de betterave sucrière. Ces estimations sont à des niveaux équivalents pour le maïs. La relation s'inverse pour les spéculations complémentaires telles que le colza et le tournesol dont les estimations, selon le produit, sont supérieures aux estimations selon la surface. 
Grandes cultures : coût de production en phytosanitaires

Tableau 3. Estimations quartiles et MCO selon la surface

\begin{tabular}{|c|c|c|c|c|c|c|c|c|c|}
\hline$€ /$ ha & & & & & & & & & \\
\hline (erreur-type) & & & Q2 & & C & & MCO & & IFT \\
\hline Blé tendre & $\begin{array}{l}140 \\
\text { (5) }\end{array}$ & $* * *$ & $\begin{array}{l}172 \\
(7)\end{array}$ & $* * *$ & $\begin{array}{r}207 \\
(9)\end{array}$ & $* * *$ & $\begin{array}{l}175 \\
(5)\end{array}$ & $* * *$ & 4 \\
\hline Blé dur & $\begin{array}{c}80 \\
(12)\end{array}$ & $* * *$ & $\begin{array}{l}137 \\
(14)\end{array}$ & $* * *$ & $\begin{array}{l}177 \\
(22)\end{array}$ & $* * *$ & $\begin{array}{c}138 \\
(8)\end{array}$ & $* * *$ & 3 \\
\hline Orge & $\begin{array}{l}98 \\
\text { (9) }\end{array}$ & $* * *$ & $\begin{array}{l}121 \\
(10)\end{array}$ & $* * *$ & $\begin{array}{l}132 \\
\text { (13) }\end{array}$ & $* * *$ & $\begin{array}{c}106 \\
(7)\end{array}$ & $* * *$ & 3,1 \\
\hline Maïs grain & $\begin{array}{l}76 \\
\text { (3) }\end{array}$ & $* * *$ & $\begin{array}{l}95 \\
(4)\end{array}$ & $* * *$ & $\begin{array}{l}120 \\
(6)\end{array}$ & $* * *$ & $\begin{array}{l}95 \\
(5)\end{array}$ & $* * *$ & 2 \\
\hline Pomme de terre & $\begin{array}{l}472 \\
\text { (33) }\end{array}$ & $* * *$ & $\begin{array}{l}549 \\
(42)\end{array}$ & $* * *$ & $\begin{array}{l}604 \\
\text { (39) }\end{array}$ & $* * *$ & $\begin{array}{l}546 \\
(14)\end{array}$ & $* * *$ & 16,9 \\
\hline Betterave sucrière & $\begin{array}{l}223 \\
(15)\end{array}$ & $* * *$ & $\begin{array}{l}256 \\
(24)\end{array}$ & $* * *$ & $\begin{array}{l}281 \\
(32)\end{array}$ & $* * *$ & $\begin{array}{l}213 \\
(16)\end{array}$ & $* * *$ & 4,5 \\
\hline Protéagineux & $\begin{array}{l}117 \\
(21)\end{array}$ & $* * *$ & $\begin{array}{l}114 \\
(21)\end{array}$ & $* * *$ & $\begin{array}{l}187 \\
(32)\end{array}$ & $* * *$ & $\begin{array}{l}138 \\
(17)\end{array}$ & $* * *$ & 4,6 \\
\hline Tournesol & $\begin{array}{c}73 \\
\text { (11) }\end{array}$ & $* * *$ & $\begin{array}{c}56 \\
(11)\end{array}$ & $* * *$ & $\begin{array}{c}54 \\
(16)\end{array}$ & $* * *$ & $\begin{array}{c}52 \\
(11)\end{array}$ & $* * *$ & 2,3 \\
\hline Colza & $\begin{array}{l}137 \\
(10)\end{array}$ & $* * *$ & $\begin{array}{l}146 \\
(13)\end{array}$ & $* * *$ & $\begin{array}{l}160 \\
(13)\end{array}$ & $* * *$ & $\begin{array}{c}162 \\
(9)\end{array}$ & $* * *$ & 6,2 \\
\hline Fourrages & & $* * *$ & $\begin{array}{l}35 \\
(6)\end{array}$ & & $\begin{array}{l}37 \\
\text { (7) }\end{array}$ & & $\begin{array}{l}28 \\
(5)\end{array}$ & $* * *$ & \\
\hline$n=2551$ & & & & & & & & & PK 2006 \\
\hline * significatif à $10 \%$ & & signif & if à $5 \%$ & & & signi & tif à $1 \%$ & & \\
\hline
\end{tabular}

3. Estimation selon les bassins de production

La comparaison peut être également menée par bassins de production, ici définis de la façon suivante : le bassin Nord \{̂̂lede-France, Champagne-Ardenne, Picardie, Haute-Normandie, Centre, Basse-Normandie, Bourgogne, Nord-Pas-de-Calais, Lorraine, Alsace, Franche-Comté, Pays de la Loire, Bretagne $\}$ et le bassin Sud \{Poitou-Charentes, Aquitaine, Midi-Pyrénées, Limousin, Rhône-Alpes, Auvergne, Languedoc-Roussillon, Provence-Alpes-Côte d'Azur, Corse \}. Les estimations des coûts obtenus pour les deux bassins de production sont présentées au tableau 4 (p. 40).

Selon l'estimation menée à partir des surfaces (partie Surface cultivée, tableau 4), le blé tendre et le blé dur apparaissent plus onéreux en phytosanitaires dans le bassin Nord que dans le bassin Sud tandis que cet ordre s'inverse pour l'orge, le maïs et le colza (excepté pour le troisième quartile de cette dernière culture). Pour les autres productions, la comparaison entre les deux bassins est plus délicate car les coefficients ne sont pas tous significatifs (certaines productions étant moins courantes dans l'un ou l'autre des bassins). Cependant, les intervalles interquartiles (définis par [Q1 ; Q3]) ne sont disjoints pour aucune des cultures où la comparaison peut être effectuée.

Sur la base des intervalles de confiance (IC) empiriques à $95 \%$ disjoints pour les processus quantiles respectifs des bassins 
Nord et Sud, la figure 2 (p. 42) confirme l'existence d'un différentiel sur le coût phytosanitaire du blé tendre pour ces deux bassins.

Ce différentiel de charges entre la moitié septentrionale et la moitié méridionale de la France est attribuable en partie à la composante fongicide des traitements sur le blé tendre, largement sous influence climatique : l'IFT fongicide est supérieur à 1,8 en Nord-Pas-de-Calais, Picardie et Basse-Normandie, tandis qu'il est inférieur à 1 et souvent proche de 0,5 dans les régions au sud de la Loire (Cassagne, 2009). La différenciation des profils de traitement phytosanitaire est induite par les conditions de production: les automnes doux et humides ainsi que les printemps frais et pluvieux, plus fréquents au nord de la Loire, constituent des conditions météorologiques favorables au développement des champignons parasites du blé tendre.

Poursuivant cette comparaison Nord/ Sud à partir des estimations selon le produit brut, les conclusions n'en diffèrent que sur les points suivants : si le blé tendre est toujours plus onéreux en phytosanitaires dans le bassin Nord, en revanche le blé dur apparaît plus onéreux en phytosanitaires dans le bassin Sud, rejoignant ainsi l'orge, le maïs grain, le colza et le tournesol. Autre différence : les coefficients des pommes de terre et des betteraves sucrières ne sont significativement différents de zéro que pour le bassin Nord.

Enfin, pour le blé dur et l'orge, les intervalles interquartiles $[Q 1 ; Q 3]$ sont disjoints entre les bassins Nord et Sud (au moins $75 \%$ des exploitations de chacun des deux bassins de production ne se situent pas dans la même échelle de coût, selon les estimations réalisées). Au total, la hiérarchie des coûts estimés en phytosanitaires demeure globalement en faveur du bassin Nord, y faisant apparaître à l'exception du blé tendre, un coût inférieur en traitements phytosanitaires pour les cultures céréalières et oléagineuses.
L'analyse en coupe diachronique sur la période 1987-2009 confirme ces éléments de différenciation entre les bassins Nord et Sud pour les coûts en phytosanitaires des céréales les plus courantes (blé tendre, orge et maïs).

\section{Estimations par groupes de dimension économique}

Afin de tester empiriquement l'existence d'économies d'échelle, nous avons regroupé les exploitations de grandes cultures en deux groupes aux poids sensiblement équivalents dans la population : d'une part, l'ensemble des exploitations dont la classe de dimension économique (Cdex) est inférieure ou égale à 8 que nous appelons Groupe $\mathrm{I}^{14}$, (tableau 5, p. 43) soit moins de 150 ha équivalent-blé en termes de marge brute standard; d'autre part, l'ensemble des exploitations dont la classe de dimension économique est supérieure ou égale à 9 (dénommé Groupe II) ${ }^{15}$, soit plus de 150 ha équivalent-blé en termes de marge brute.

Pour les céréales, les coûts estimés en phytosanitaires du Groupe I sont supérieurs à ceux relatifs au Groupe II. Néanmoins, ces différences apparaissent significatives seulement pour l'orge dont les intervalles interquartiles respectifs de ces deux grands groupes de dimension économique sont disjoints dans l'estimation selon le produit brut. Pour les cultures industrielles, la hiérarchie des coûts est inversée bien que les écarts soient moins importants. Pour les oléagineux, les coûts en phytosanitaires du tournesol sont supérieurs pour le Groupe I alors que c'est l'inverse pour le colza où les coûts phytosanitaires du Groupe II apparaissent supérieurs si l'on s'appuie sur la distribution des quartiles. L'analyse en coupe diachronique sur la période 19872009 montre des intervalles de confiance

14. Agrégation des Cdex 5, 6, 7 et 8 du RICA. 15. Agrégation des Cdex 9 et 10 du RICA. 
Grandes cultures : coût de production en phytosanitaires

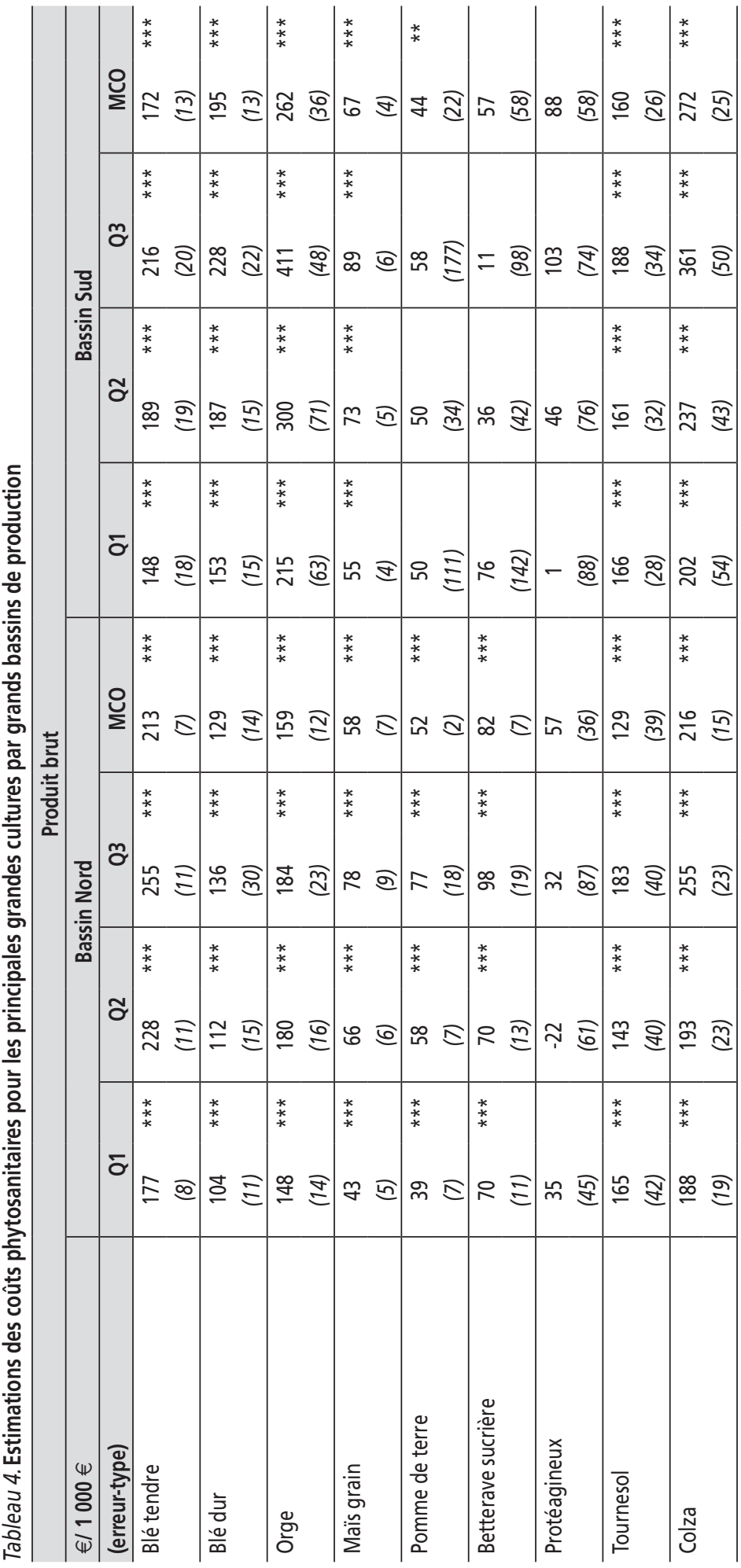

40 • Économie Rurale 333/Janvier-Février 2013 
RECHERCHES

Dominique DESBOIS, Jean-Pierre BUTAULT, Yves SURRY

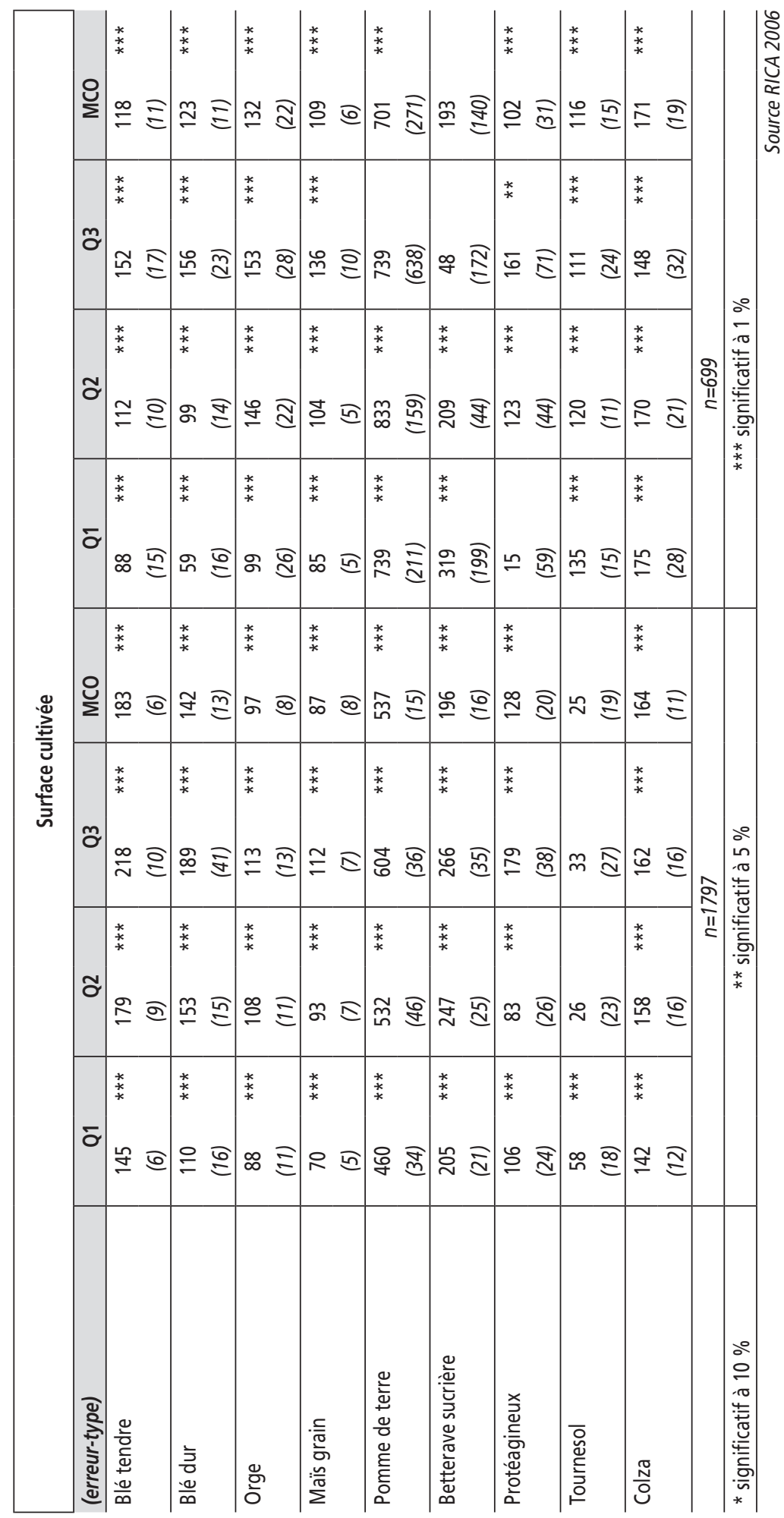




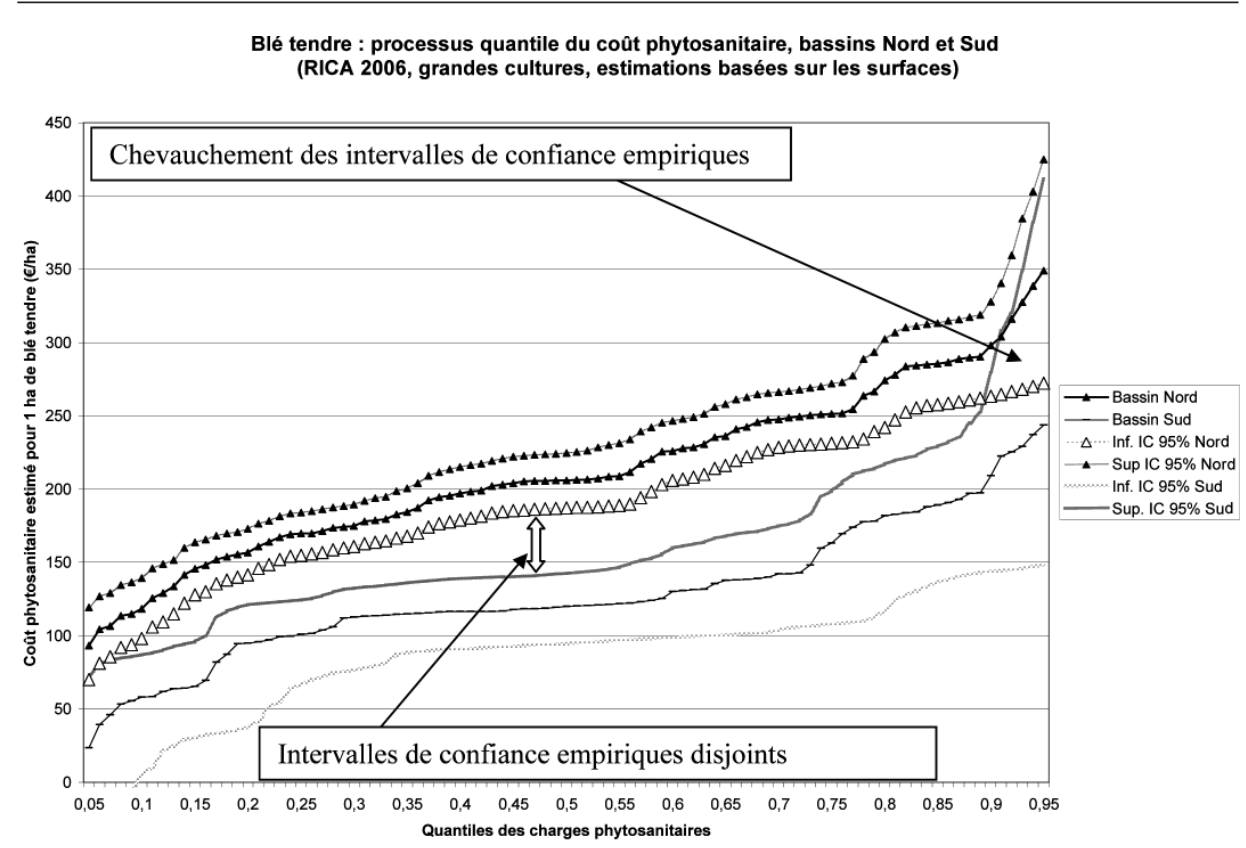

empiriques du Groupe I et du Groupe II se chevauchant pour les grandes cultures, à l'exception du blé tendre et la betterave sucrière où ils sont disjoints en 2008 et 2009.

Aux exceptions de l'orge en 2006 et, plus récemment en 2008 et 2009 , du blé tendre et de la betterave sucrière, il n'apparaît donc pas de différences significatives entre coûts phytosanitaires qui soient liés à la dimension économique. Selon les règles de décision utilisées, il n'y a donc pas d'éléments concluants en faveur de l'existence d'économies d'échelle.

\section{Estimations selon les orientations technico-économiques}

La comparaison entre les différentes orientations technico-économiques (Otex) en grandes cultures permet d'apprécier l'impact d'une plus grande spécialisation (par exemple, spécialisation de l'Otex 13 en cultures céréalières et oléo-protéagineuses ou spécialisation de l'Otex 14 en cultures industrielles comme la pomme de terre de féculerie ou la betterave sucrière) ou d'une plus grande diversification productive (par exemple, pour l'Otex 81 entre grandes cultures et élevage herbivore).

Selon les estimations réalisées d'après les produits bruts (tableau 6, p. 46), la significativité des coefficients de charges phytosanitaires est différente selon les orientations technico-économiques: les coefficients de la pomme de terre significatifs pour l'Otex 14, ne le sont pas tous ${ }^{16}$ pour l'Otex 13, témoignant du caractère marginal de cette culture pour certains quartiles de cette orientation ; c'est le cas également des protéagineux, du tournesol et du colza pour l'Otex 14.

A contrario, certaines cultures peuvent apparaître, du fait d'une grande significativité des coefficients, comme intégrées de manière standard aux assolements

16. Au niveau de confiance de $95 \%$. 


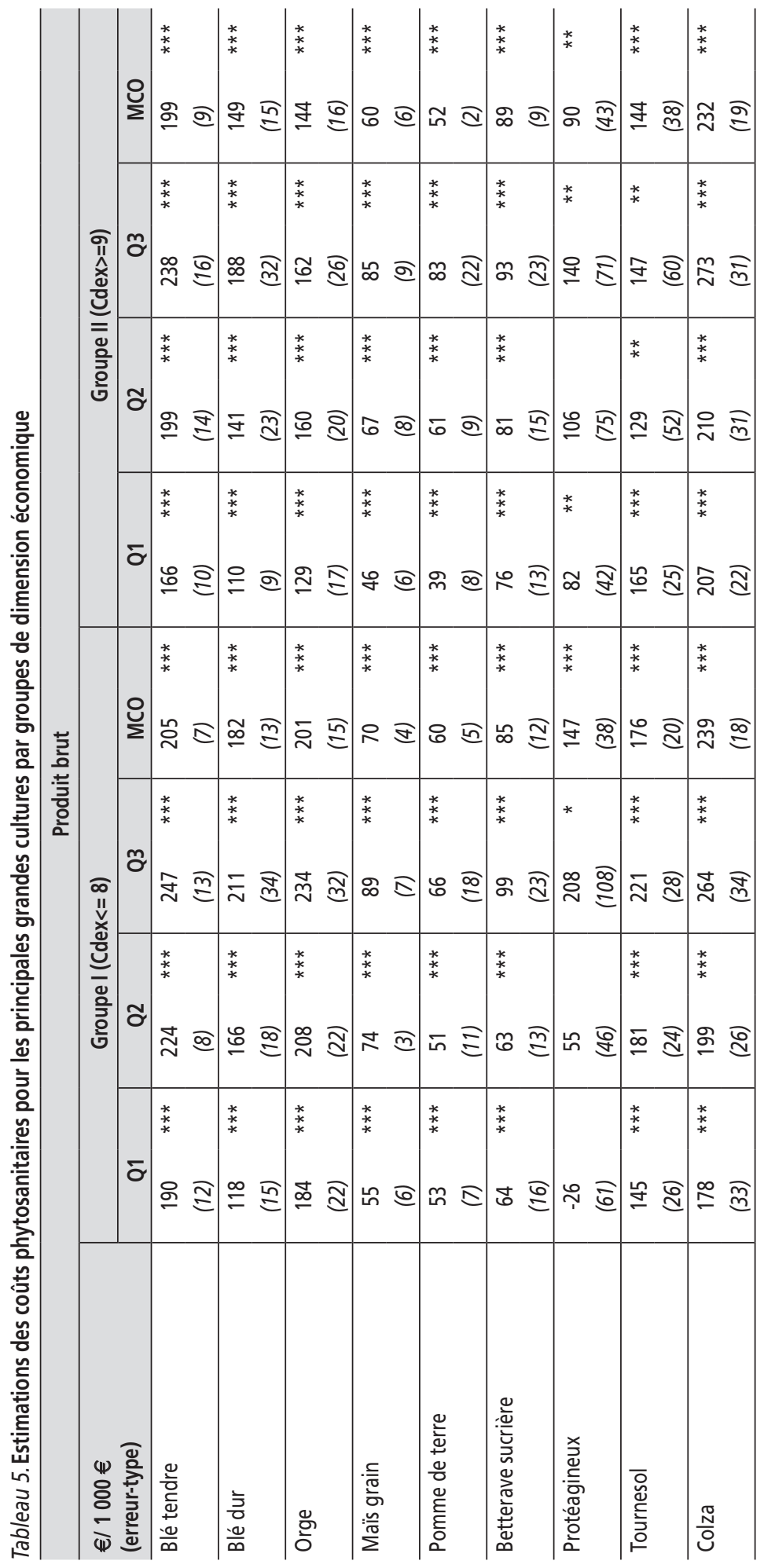


Grandes cultures : coût de production en phytosanitaires

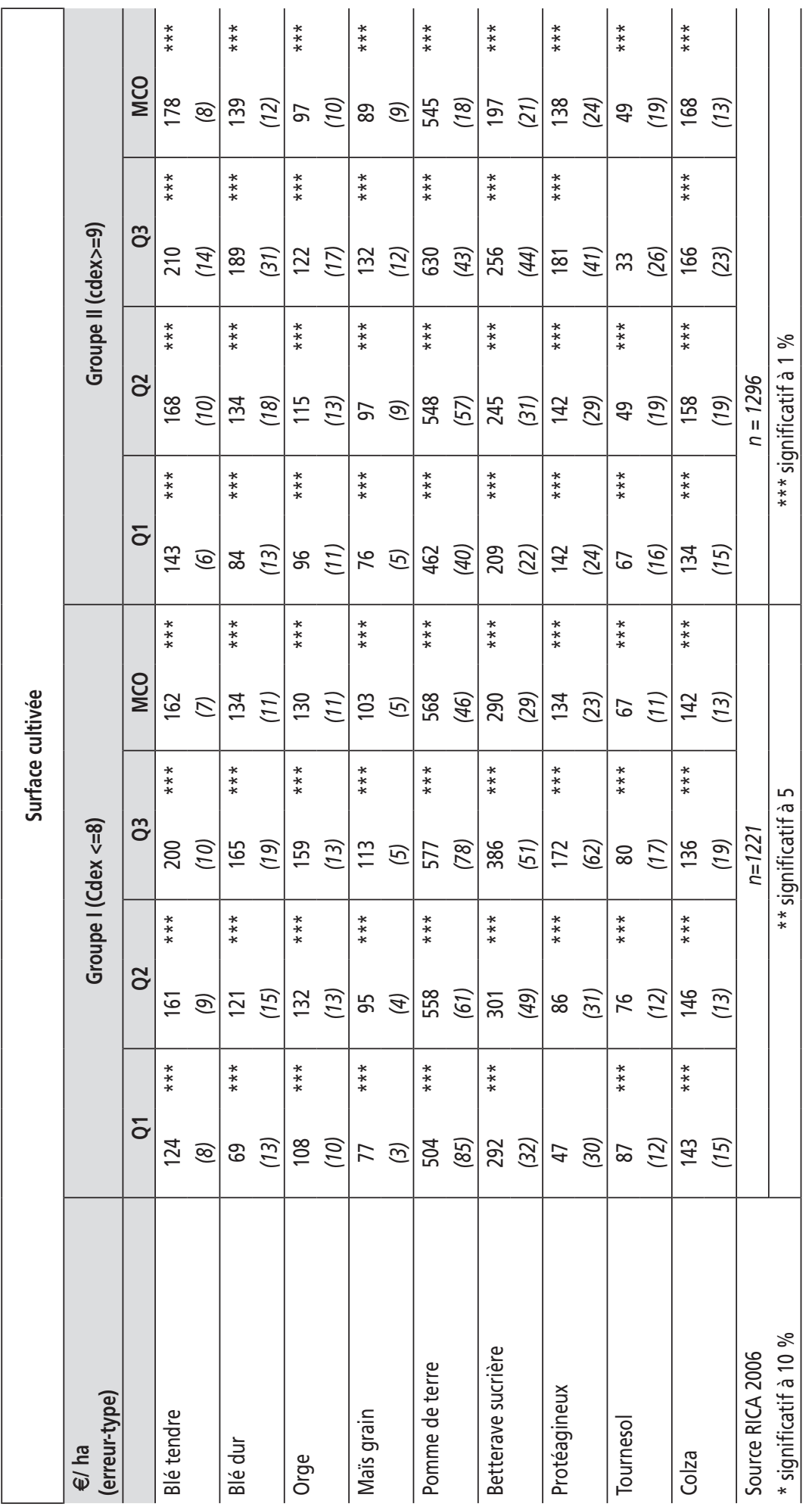


(par exemple, la pomme de terre pour l'Otex 14). Pour le blé tendre, les intervalles interquartiles de coût phytosanitaire sont disjoints entre l'Otex 13 (coûts inférieurs) et l'Otex 14 ; pour la betterave sucrière également, avec l'Otex 14 (coûts inférieurs) versus l'Otex 13 ; c'est quasiment le cas pour le maïs grain entre l'Otex 13 (coûts inférieurs) et les Otex 14 et 81 ; ces différences significatives refléteraient des profils distincts de traitement induits par les facteurs sous-jacents à la spécialisation soit en céréales-oléo-protéagineux, soit en cultures industrielles. Ces écarts de coût résulteraient en partie de rotations culturales spécifiques à chacune des orientations de grandes cultures, dont l'allongement ou la rupture des cycles culturaux permettraient par exemple de mieux contrôler les infestations.

D'après les estimations réalisées selon les surfaces, le niveau des coûts par hectare est plus élevé pour les céréales dans l'Otex 14, relativement aux autres Otex de grandes cultures (13 et 81). Par contre, le niveau des dépenses phytosanitaires y apparaît considérablement plus faible en betteraves industrielles, relativement aux autres Otex de grandes cultures ; ce phénomène est beaucoup moins marqué pour l'autre culture industrielle majeure qu'est la pomme de terre.

Pour le blé tendre, les intervalles interquartiles sont disjoints entre l'Otex 13 (coûts inférieurs) et l'Otex 14 ; de même en maïs, pour l'Otex 13 (coûts inférieurs) contre l'Otex 14, ou encore inversement en betteraves sucrières, coûts inférieurs pour l'Otex 14 contre l'Otex 13 et l'Otex 81, attribuables à une plus grande spécialisation en cette culture.

Ces différences, jugées significatives selon un critère d'absence de chevauchement des intervalles inter-quartiles, apparaissent compatibles voire cohérentes avec la spécialisation relative de chaque Otex de grande culture. Une méthodologie plus élaborée permettrait d'affiner ces tests par le calcul d'un risque de première espèce.

L'analyse en coupe diachronique sur la période 1987-2009 confirme, pour le blé tendre et le maïs, des coûts phytosanitaires significativement inférieurs pour l'Otex 13 à ceux de l'Otex 14, divergents à compter de 1994. De même, pour la betterave sucrière, les coûts phytosanitaires de l'Otex 14 sont inférieurs à ceux de l'Otex 13 sur l'ensemble de la période. On peut voir dans ces évolutions divergentes des coûts phytosanitaires un indice de la spécialisation de plus en plus marquée de ces deux orientations.

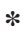

Notre article montre comment la régression quantile peut être appliquée aux problèmes d'estimation des dépenses phytosanitaires par culture selon l'information technique et comptable disponible: produits bruts et surfaces cultivées. L'application de cette procédure économétrique à des exploitations agricoles françaises nous permet de conclure que des différences significatives de coûts phytosanitaires ont existé d'une part entre les bassins de production Nord et Sud, et d'autre part entre les exploitations spécialisées en céréales, oléagineux et protéagineux et celles spécialisées en cultures industrielles. Par contre, à l'exception de l'orge, il n'y a aucune indication qu'il y ait eu des différences significatives de coûts phytosanitaires entre les classes de dimension économique. L'analyse menée en fonction des estimations quartiles illustre le potentiel exploratoire offert par l'ensemble du processus quantile issu de cette méthodologie de régression par rapport aux estimations obtenues par les moindres carrés ordinaires. En combinant ces deux procédures économétriques, il est donc possible d'obtenir une photographie complète sur la distribution des coûts phytosanitaires par grande culture, 


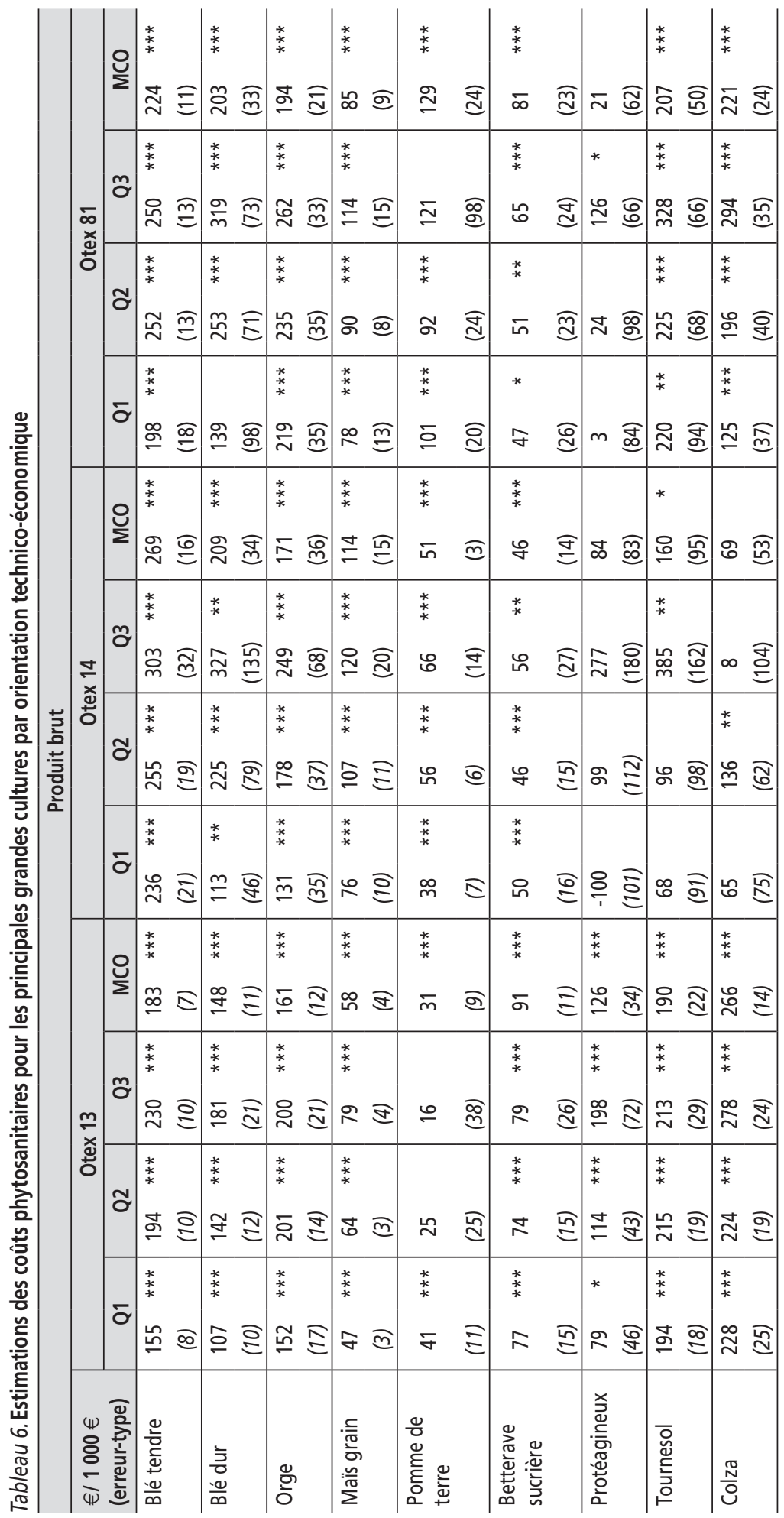


RECHERCHES

Dominique DESBOIS, Jean-Pierre BUTAULT, Yves SURRY

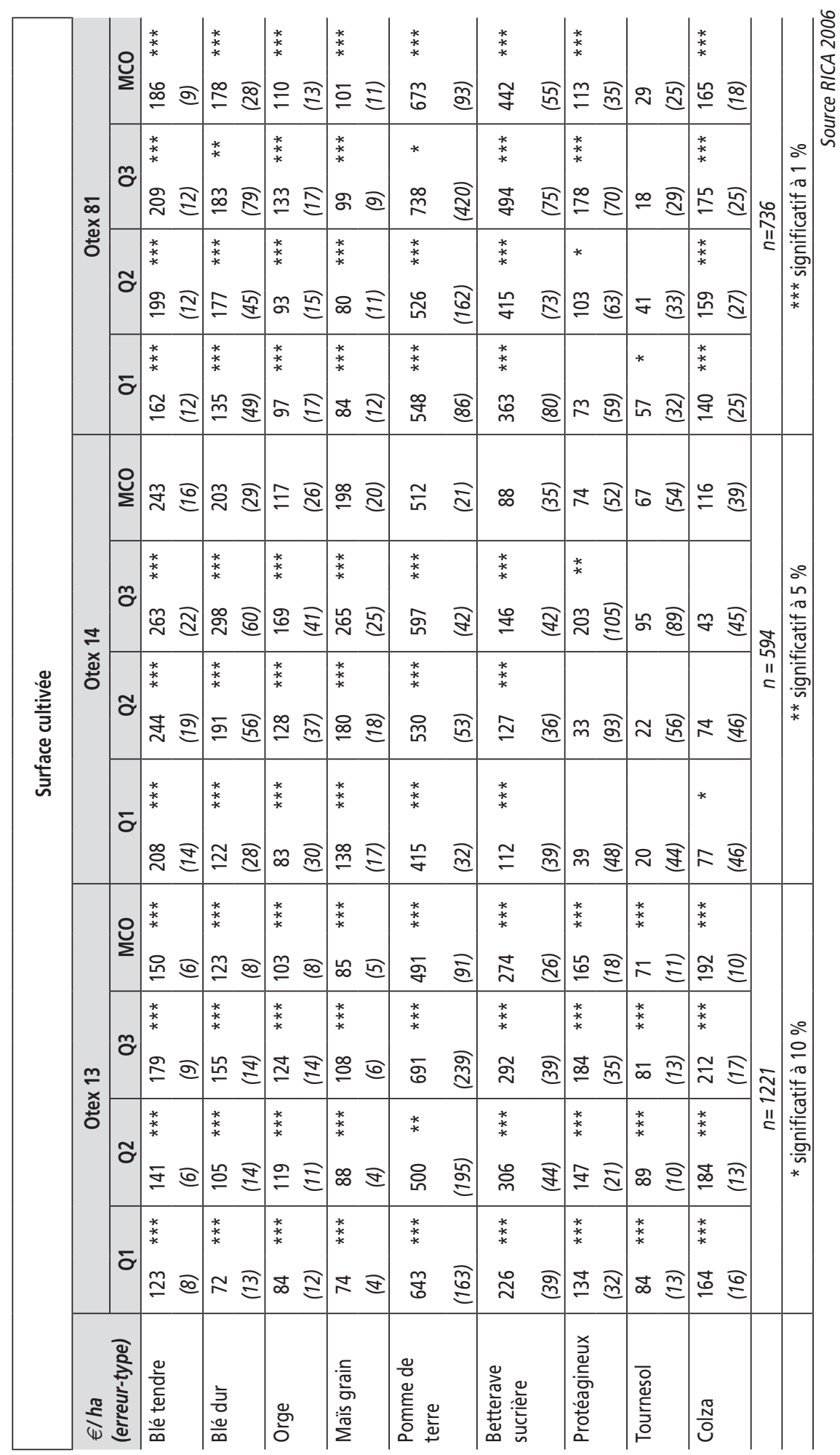




\section{Grandes cultures : coût de production en phytosanitaires}

que ce soit en termes de caractéristiques de tendance centrale (moyenne et médiane) qu'en termes de distribution (dispersion et évolution de ces coûts aux queues de cette distribution). En conséquence, ce type d'information quantitative sur la distribution des coûts phytosanitaires peut contribuer à faciliter la mise en place au niveau français ou européen de politiques publiques visant à réduire l'emploi de pesticides.

Les intervalles de confiance empiriques du processus quantile ont été utilisés comme règle de décision pour établir qu'une différence significative existe entre les niveaux de coûts phytosanitaires. Cependant, un tel test ne fournit qu'une réponse binaire. La mise en œuvre d'un test basé sur les propriétés asymptotiques des estimateurs quantiles permettrait de calculer un risque de première espèce. Nous avons étendu la validation empirique aux bassins de grandes cultures homogènes du point de vue des conditions de production, mobilisant les informations comptables recueillies par la sonde Grandes cultures du RICA pour calculer les marges brutes. La base d'information du Centre d'économie rurale de la Meuse réunit des informations comptables de nature analytique, incluant les dépenses phytosanitaires allouées aux principales cultures sur une base déclarative par les exploitants agricoles : elle constitue un échantillon-test pour une validation partielle de la méthodologie, extensible à d'autres départements comme celui d'Eure et Loir.

Nous proposons d'analyser les différences jugées significatives en termes de pratiques culturales en réponse à des contextes phytosanitaires distincts : l'utilisation de l'IFT devrait permettre d'obtenir des estimations de coût par traitement à l'hectare de culture traitée, selon différents contextes de production précisés à l'échelle régionale. L'utilisation des données de l'enquête Pratiques culturales 2006 permettrait d'affiner l'analyse en fonction des profils de traitement et du poids respectif de leurs différentes composantes (herbicide, insecticide et fongicide). Le contexte pédologique intervenant dans l'adoption d'un système de cultures, la mobilisation de typologies régionales délimitant des regroupements de contextes de production homogènes permettrait également de mieux analyser la variabilité des dépenses phytosanitaires.

Les aléas climatiques étant un déterminant majeur des phytopathologies, des analyses sont en cours sur une période permettant d'apprécier leur influence sur le niveau et la variabilité des coûts phytosanitaires. Les conclusions de l'analyse en coupe diachronique sur la période 1987-2009 seront donc étendues au fur et à mesure de la disponibilité des données du RICA pour être confrontées avec celles qui peuvent être tirées d'analyses sur données de panel.

Enfin, l'extension de cette analyse aux pays européens mettant à disposition des données similaires permettrait de tester des hypothèses de différenciation au plan des bassins de production et de la dimension des exploitations ainsi que la mise en œuvre d'une analyse de sensibilité des résultats à la prise en compte ou non des pondérations d'échantillonnage.

Cette recherche a bénéficié $d$ 'un financement $d u$ 7 Programme Cadre de la Communauté européenne (FP7/2007-2013) sous l'agrément $n^{\circ}$ 212292. (Farm Accountancy Cost Estimation and Policy Analysis of European Agriculture, http:// facepa.slu.se) 


\section{RÉFÉRENCES BIBLIOGRAPHIQUES}

Barrodale I., Roberts F.D.K. (1973). An improved algorithm for discrete $1_{1}$ linear approximation. SIAM Journal of Numerical Analysis, vol. 10, p. 839-848.

Boussemart J.-P., Leleu H., Ojo O. (2011). Could society's willingness to reduce pesticide use be aligned with farmer's selfinterest? Ecological Economics, vol. 70, p. 1797-1804.

Bureau J. C., Cyncynatus M. (1991). Estimation de coûts de production et de coefficients input-output à partir de données comptables: méthodes et applications aux produits agricoles sur la base du RICA. Économie et Sociologie Rurales, Notes et Documents n³8, INRA, Département Économie et Sociologie Rurales, 87 pages.

Cameron A. C., Trivedi P. K. (2005). Microeconometrics. Methods and Applications. Cambridge, Cambridge University Press.

Cassagne J.-P. (2009). La protection phytosanitaire du blé tendre. Davantage de traitements pour les cultures à hauts rendements. Agreste Primeur, n²26, juin, 4 p.

Chapelle-Barry C. (2008). Enquête sur les pratiques culturales en 2006. Agreste Chiffres et Données, Série Agriculture, n²00, août, $137 \mathrm{p}$.

Desbois D., Pollet P. (2002). Évaluation de la marge brute standard sur la base du RICA. Insee Méthodes, $\mathrm{n}^{\circ} 101$, INSEE, p. 395-429.

Deville J.-C., Särndal C.-E., Sautory O. (1993). Generalized ranking procedures in survey sampling. Journal of the American Statistical Association, vol. 88, n²23, p. 1013-1020.

Jacquet J., Butault J-P., Guichard L. (2011). An economic analysis of the possibility of redu- cing pesticides in French field crops. Ecological Economics, vol. 70, p. 1638-1648.

Karmakar R. (1984). A new polynomial-time algorithm for linear programming. Combinatorica, $\mathrm{n}^{\circ} 4$, p. 373-395.

Koenker R. (2005). Quantile regression. Cambridge, Cambridge University Press.

Koenker R., Bassett G. (1978). Regression quantiles. Econometrica, vol. 46, p. 33-50.

Koenker R., d'Orey V. (1994). Remark AS R92: A remark on algorithm AS 229: Computing dual regression quantiles and regression rank scores. Applied Statistics, vol. 43, p. 410-414.

Koenker R., Zhao Q. (1994). L-estimation for linear heteroscedastic models. Journal of Nonparametric Statistics, vol. 3, p. 223-235.

Lustig I. J., Marsden R. E., Shanno D. F. (1992). On implementing Mehrotra's predictor-corrector interior-point method for Linear Programming. SIAM Journal on Optimization, $\mathrm{n}^{\circ} 2$, p. 435-449.

OCDE (2008). Pesticides. Environmental Performance of Agriculture since 1990. Paris, Main Report, OCDE, p. 63-75.

Paillotin G. (2008). Chantier 15 «agriculture écologique et productive. Paris, Rapport final du président du Comité opérationnel « Ecophyto 2018 », Grenelle de l'environnement, MAAP, 138 p.

Pollet P., Butault J.-P., Chantry E.(1998). Le modèle sur les coûts de production agricole. Document de travail INSEE, ${ }^{\circ}$ E9802, 72 p.

Portnoy S., Koenker R. (1997). The gaussian hare and the laplacian tortoise: Computation of squared-errors vs. absolute-errors estimators. Statistical Science, vol. 1, p. 279-300. 